кУЛЬтУРОЛОГИЯ

DOI: $10.17805 /$ trudy.2017.1.1

\title{
ПРАВОВЫЕ ЦЕННОСТИ КУЛЬТУР И СОВРЕМЕННЫЕ ПРОЦЕССЫ РЕГИОНАЛИЗАЦИИ
}

\author{
И. И. Погорлецкая \\ Приднестровский государственный университет им. Т. Г. Шевченко; \\ Московский гуманитарный университет
}

Аннотация: В статье раскрываются особенности правовых ценностей западной, азиатской и мусульманской правовых культур, а также связанные с ними происходящие процессы регионализации.

Статья подготовлена на основе доклада автора на ХІІІ Международной научной конференции «Высшее образование для ХХІ века» (8-10 декабря 2016 г., Московский гуманитарный университет).

Ключевые слова: правовые ценности; культурные ценности; западная культура; азиатская культура; мусульманская культура; процесс регионализации

\section{LEGAL VALUES OF CULTURES AND CONTEMPORARY PROCESSES OF REGIONALIZATION}

\author{
I. I. Pogorletskaia \\ Pridnestrovian State University named after Taras Shevchenko; \\ Moscow University for the Humanities
}

\begin{abstract}
The article reveals the peculiarities of legal values of Western, Asian and Muslim legal cultures, as well as related processes of regionalization.

The article is based on the author's presentation given at the 13th International Scientific Conference «Higher Education for the 21st Century» (8-10 December 2016, Moscow University for the Humanities).

Keywords: legal values; cultural values; Western culture; Asian culture; Muslim culture; regionalization
\end{abstract}

Актуальность статьи обусловлена тем, что в условиях современного мира наряду с процессом универсализации прав человека и выработки универсальных правовых ценностей, активизировался процесс регионализации, т. е. дальнейшего развития национальных правовых ценностей и создания стандартов в области защиты прав человека в регионах, исходя из их культурных и исторических особенностей (Погорлецкая, 2016). 
Раскрывая природу национальных правовых ценностей, следует сказать, что их характер и специфика зависят от конкретных культурноисторических особенностей общественного развития. Традиционно протестантские, православные, исламские, конфуцианские страны отличаются собственными ценностно-правовыми системами, которые четко прослеживаются на всех этапах социально-экономического развития.

Национальные правовые ценности можно определить как такие ценности, которые «отражают совокупность особенностей образа жизни и мышления отдельного сообщества и выражаются, в первую очередь, во внутринациональном... законодательстве» (Мишутина, 2011: 165).

На основе национальных правовых ценностей формируется единое национальное правосознание, которое выступает необходимым условием обеспечения целостности всех политико-правовых институтов государства и общества.

Для западной правовой традиции характерными являются ценности, основанные на уважении к правам человека, свободе, справедливости, демократии и господстве закона. В основе европейских правовых ценностей лежит наследие античности, с ее представлениями об окружающем мире как гармоничном целом; римском частном праве, заложившем правовые основы европейской цивилизации; христианства послужившего основой духовной культуры современной Европы. Многовековая борьба между светской и духовной властями завершилась в Европе отделением в большинстве европейских стран церкви от государства, школы от церкви, принятием Конституций и закреплением в них секулярного принципа свободы совести, не допускающего дискриминации за религиозные убеждения или их отсутствие. Западная модель правовых ценностей формировалась в условиях поиска оптимального механизма регулирования отношений между личностью и государственными структурами, а также противостояния граждан произволу властей. Для западной правовой традиции характерно обособление человека от общества, индивидуализация личности, преобладание решения проблем преимущественно юридическими средствами. Западные правовые ценности выступают как сфера свободы и автономии личности, недопустимости вмешательства в частную жизнь, равенство перед законом и судом, право на одинаковую меру свободы, на защиту своих прав в случае их нарушения способами, не запрещенными законом и т. д. В настоящее время ценности свободы, правового равенства, социальной справедливости, уважение личности, ее жизни, достоинства, неприкосновенности права частной собственности закреплены Хартией прав человека Совета Европы и Хартией Европейского Союза по основным правам человека.

Следует сказать, что западные правовые ценности фундаментально отличаются от правовых ценностей, присущих другим цивилизациям. В 
мусульманской, конфуцианской, буддистской правовых культурах фактически не находят отклика такие западные правовые ценности, как демократия, правовое равенство, свобода, в том числе свобода совести, отделение церкви от государства и др. Настойчивая пропаганда западных правовых ценностей зачастую вызывает враждебную реакцию со стороны не западных государств. В этой связи имеет смысл концепция С. Хантингтона, согласно который в условиях многополярного мира наиболее целесообразным является не его вестернизация, влекущая геополитические конфликты, а дальнейшее развитие государств на основе достижений собственной цивилизации.

Говоря об американских правовых ценностях, следует сказать, что они основаны на идеалах американского общества, которые уходят корнями в историю государства и религии Америки. Ф. Хсю в работе «Базовые американские ценности и национальный характер» дает список американских ценностей: моногамный брак, свобода, восприимчивость, демократия, образование, монотеизм, и наука (Хсю, Электр. ресурс). К числу правовых ценностей, закрепленных в американской Конституции, можно отнести свободу, равенство, собственность, демократию. Также американцы уделяют большое внимание таким правовым ценностям как человек, его права и свободы, закон и правопорядок, справедливость.

Особое отношение у американцев существует к ценности свободы. Данное право настолько защищается конституцией, что, несмотря на жалобы некоторых людей, относительно слишком лояльного отношения к лицам, совершившим преступления, они уверенны в легитимности действий как правоохранительных органов, так и судебных решений. Тем самым, западные правовые ценности, которые включают правовые ценности Западной Европы и Америки, имеют ряд общих черт: ценность человеческой личности, уважение ее достоинства, ценность свободы, справедливости, равенство мужчин и женщин, неприкосновенность права частной собственности.

Для азиатской правовой традиции характерно утверждение единства общества и человека, уважение к государственной власти. В отличие от европейского и американского мировоззрения в азиатской системе ценностей интересы общества ставятся выше интересов индивида. Само общество ставится целью существования человека, власть в котором основана на осознании естественного неравенства. По словам Го Чок Тонга, азиатские ценности включают в себя «чувство сообщества и принадлежности к нации, дисциплинированный и трудолюбивый народ, крепкие нравственные ценности и семейные узы ... чувство идеализма и служения, порожденное ощущением общественной солидарности и национальной идентификации» (Goh, 1994: Электр. ресурс). 
Кроме того, обеспечение социально-экономических прав в некоторых азиатских государствах рассматривается как задача первостепенной важности, а юридические гарантии относятся к вторичным средствам защиты прав человека. В отличие от европейских государств, где сложилась антропоцентрическая модель миропорядка с представлениями о правах человека на жизнь, свободу, собственность, личное достоинство, азиатская система правовых ценностей исходит из приоритета интересов общества и принципа социальной гармонии.

В научной литературе существует концепция так называемых «азиатских ценностей», которая исходит из приоритетов интересов общины, а также направленностью на достижение высоких темпов экономического роста и социального благополучия граждан. К числу сторонников «азиатских ценностей» можно отнести Ли Куан Ю (Lee Kuan Yew) (руководителя Сингапура 1959-1990 гг.), Махатхир бен Мухаммеда (руководителя Малайзии 1981-2003 гг.), Ху Цзиньтао (руководитель Китая 2002-2012 гг.), Фердинанда Маркоса (Президент Филиппин 1965-1986 гг.), Сусило Бамбанг Юдойоно (Президента Индонезии 2004-2014 гг.).

Сторонники «азиатских ценностей» утверждают, что ограничение политических прав в их странах оправдано интересами сохранения стабильности и эффективного экономического развития. Как отмечают И.А.Филатова и Н. П. Дронишинец, «Премьер-министр Сингапура Ли Куан Ю для объяснения поразительных успехов некоторых стран Азии в экономической сфере, а также для оправдания его собственного варианта патерналистского авторитаризма утверждал, что азиатская культура, делая упор на подчинении авторитету группы, трудолюбии, семье, сбережениях и образовании, была решающим фактором быстрого, не имеющего прецедентов послевоенного экономического роста в Азии» (Филатова, Дронишинец, 2011: 82).

Истоки различия западных и азиатских правовых ценностей лежат в культурно-исторических условиях, когда «права возникают в определенном социальном, экономическом и культурном контексте. Те условия, которые способствовали институционализации прав человека на Западе, не существуют в Азии. Благодаря огромным различиям в историческом прошлом, социальных системах, культурной традиции и экономическому развитию, страны разнятся в своем понимании и практике прав человека» (Моисеев, 2014: Электр. ресурс). Согласно «азиатской» системе взглядов на европейские правовые ценности, они имеют индивидуалистическую природу и разрушительны для социальных механизмов Азии. И действительно, как справедливо замечает Н. С. Цинцадзе, «совершенно очевидно, что европейские либеральные ценности, рожденные буржуазными революциями XVII-XVIII вв., ставшие основой для многих 
политико-правовых ценностей, возникших в результате создания демократических государств, не являются универсальными для стран Азии, Африки и Латинской Америки» (Цинцадзе, 2015: 44). Тем самым, можно согласиться с С. В. Моисеевым в том, что «азиатские общества значительно меньше, чем западные, ценят свободу и значительно больше - порядок и спокойствие. Их отличает уважение к власти... они высоко ценят коллективизм, солидарность и отвергают индивидуализм. Интересам сообщества и общества в целом отдается предпочтение перед интересами индивида...» (Моисеев, 2014: Электр. ресурс).

В целом можно сказать, что первостепенное значение для азиатского общества имеют такие социально-экономические правовые ценности как: право на занятие предпринимательской деятельностью, право на труд, право собственности, право наследования, право на жилище и т. д. Меньшая роль отводится политическим и личным правовым ценностям (свободу слова, печати, совести, собраний, неприкосновенность жизни азиатские государства в большинстве случаев не отказались от смертной казни, свободу передвижения, переписки и т. д.).

Тем не менее, нельзя отрицать, что в последнее время в азиатских государствах социально-экономические приоритеты развития общества отходят на задний план, уступая место личным правовым ценностям. В данных государствах происходит понимание того, что гармоничное развитие общества создает условия для всестороннего развития личности. Закрепление и реализация свободы личности в азиатских государствах позволит обратиться в качестве ценностных приоритетов к духовным традициям, весьма характерным для буддийского сознания.

Для мусульманских обществ, основанных на традиции, в числе основополагающих ценностей можно назвать принцип умеренности, которые находит отражение в политике, экономике, социальной сфере и личном поведении. Основной категорией в исламе являются не права человека, а его обязанности. А. Л. Могилевский отмечает, что «догматы веры не предоставляют прав мусульманину, у него имеются лишь обязательства перед Всевышним» (Могилевский, 1997: 142-143). В исламском обществе выделяются и подлежат защите такие основные правовые ценности как жизнь, собственность и религия. Религиозные догматы выступают источником права и являются основой регулирования брачно-семейных, наследственных и др. правоотношений. В отличие от других религий мира, ислам значительно глубже охватил все сферы человеческих отношений и на протяжении многих веков выступал в качестве их универсального регулятора. Особенно велико его влияние на организацию семейнобытовых отношений, на формирование обыденного сознания мусульман (Вагабов, 1988: 26). 
В отличие от либерально-демократических представлений относительно государственного устройства, закрепленных в нормах международного права, в исламском обществе господствует теократическая концепция государства, которое имеет значение лишь с позиции служителя установленной религии. Исламское общество сакрализирует политическую власть, и религия приобретает государственный статус, освещая политическую традицию.

Следует также отметить, что исламские государства характеризуются рядом специфических черт. В частности, в данных государствах наряду с изощренным исполнением смертной казни (забитее камнями, предварительное отсекание конечностей), существует ряд телесных наказаний (удары плетью). Сметная казнь предусматривается за супружескую измену, отречение от ислама, что, с точки зрения западного правосознания, является грубейшим нарушением прав человека и вмешательством в частную жизнь. Не согласуется с западными представлениями на права человека отсутствие равенства между мужчиной и женщиной, а также законодательный запрет на занятие не мусульманами определенных государственных должностей в исламских государствах - например, поста главы государства, судьи, что основано на положениях Корана: «Не повинуйся неверным...» (25:52) (Сюкияйнен, 2008). Тем самым, в отличие от стран европейской правовой традиции в странах исламской правовой культуры религиозно-нравственные нормы играют роль юридически закрепляемых прав и свобод человека.

Следует также сказать, что если западная концепция правовых ценностей исходит из совокупности сформулированных самим человеком и закрепленных государством правовых ценностей, то в основе мусульманских прав и свобод лежит божественная воля, выраженная в шариате - Коране и сунне Пророка. Кроме того, принципиальное отличие в понимании правовых ценностей заключается в том, что западная правовая традиция ищет источник правовых ценностей в природе человека, а ислам таким источником считает шариат, т. е. «божественный закон».

В области экономических прав и свобод между западными, азиатскими и исламскими правовыми ценностями нет существенных отличий. Такая ситуация характерна для гражданского и коммерческого оборота даже тех современных мусульманских стран, где позиции шариата наиболее прочны. Однако, в мусульманских государствах не смотря на достигнутый общественный прогресс, экономическое, политическое и духовное развитие, общество не перестает опираться на привычные, традиционные устои.

Рассмотренные нами западные, азиатские и мусульманские общества с присущими им правовыми ценностями сформировались под влиянием 
соответствующего типа культурной традиции. Западные правовые ценности сформировались преимущественно под влиянием протестантской, азиатские - конфуцианской, мусульманские - исламской культурноправовой традиции. Также можно сделать вывод, что мусульманские и азиатские правовые ценности, во многом совпадают с западными в области экономических, социальных, торговых и культурных правовых ценностей. Относительно же личных прав и свобод, а также политических правовых ценностей в мусульманских и азиатских государствах, можно сказать, что они совпадают с западными правовыми ценностями только в части, которая не противоречит национальными правовым особенностям и традициям.

\section{СПИСОК ЛИТЕРАТУРЫ}

Вагабов, М. В. (1988) Ислам и проблемы формирования атеистического мировоззрения молодежи. Махачкала: Дагучпедгиз. 119 с.

Мишутина, Э. И. (2011) Ценностный подход к модернизации правовой системы // Проблемы модернизации правовой системы современного российского общества, междунар. науч. конф. (2010; Красноярск). Международная научная конференция Проблемы модернизации правовой системы современного российского общества, 30 сент. - 1 окт. 2010 г. сб. докладов: в 2 т. / отв. ред. В. М. Шафиров. Красноярск: Центр информации. 476 с. Т. 1.

Моисеев, С. В. (2014) «Азиатские ценности» и права человека: некоторые теоретические аспекты дискуссии [Электронный ресурс] // Центрально-азиатский толстый журнал. http://ctaj.elcat.kg/2014/06/22/ aziatskie-cennosti-i-prava-cheloveka-nekotorye-teoreticheskie-aspektydiskussii/ (дата обращения: 12.11.2016).

Могилевский, А. Л. (1997) Правосознание и религия. Ашхабад : Ылым. 268 c.

Погорлецкая, И.И.(2016) Актуальные проблемы соотношения универсальных и национальных правовых ценностей в условиях современных обществ // Знание. Понимание. Умение. № 2. С. 307-319. DOI: 10.17805/ zpu.2016.2.27

Сюкияйнен, Л. Р. (2008) Исламское уголовное право: от традиционного к современному // Российский ежегодник уголовного права. № 2 . С. 571-596.

Цинцадзе, Н. С. (2015) Соотношение государственно-правовых ценностей и приоритетов в аксиологии государства и права // Ленинградский юридический журнал. № 2 (40). С. 43-52.

Хсю, Ф. Базовые американские ценности и национальный характер [Электронный ресурс] // Библиотечная система. Международный университет природы, общества и человека «Дубна». URL: http://lib.uni-dubna.ru/ 
search/files/kult_hsyu/ kult_hsyu.htm (дата обращения: 12.11.2016).

Филатова, И. А., Дронишинец, Н. П. (2011) Азиатские ценности в восточноазиатском образовании в условиях глобализации // Специальное образование. № 2. С. 76-87.

Goh, Chok Tong (1994) Social Values, Singapore Style, Current History. op. by: S. Moses «Asian values» and human rights: some theoretical aspects of the debate [Электр. ресурс] // Центральноазиатский толстый журнал. URL: http:/ctaj.elcat.kg/2014/06/22/aziatskie-cennosti-i-prava-chelovekanekotorye-teoreticheskie-aspekty-diskussii/ (дата обращения: 12.11.2016).

Дата поступления: 07.12.2016 2.

Погорлецкая Ирина Ивановна - старший преподаватель кафедры гражданского права и гражданского процесса юридического факультета Приднестровского государственного университета им. Т. Г. Шевченко, аспирант кафедры философии, культурологи и политологии Московского гуманитарного университета. Адрес: 3300, Молдавия, г. Тирасполь, ул. Мира, д. 18. Тел.: +(373) 77547942. Эл. адрес: begass.iren@mail.ru Научный руководитель - д-р политол. н., проф. В. И. Буренко.

Pogorletskaya Irina Ivanovna, Senior Lecturer, Department of Civil Law and Civil Procedure, Faculty of Law, Pridnestrovian State University named after Taras Shevchenko; Postgraduate Student, Department of Philosophy, Culturology and Politology, Moscow University for the Humanities. Postal address: 18 Mira St., Tiraspol, Moldova 3300. Tel.: + (373) 77547942. Scientific Adviser - V. I. Burenko, Doctor of Politology, Professor.

\section{Для цитирования:}

Погорлецкая И. И. Правовые ценности культур и современные процессы регионализации [Электронный ресурс] // Научные труды Московского гуманитарного университета. 2017, № 1. URL: http://journals.mosgu.ru/trudy/article/view/392 (дата обращения: дд.мм.гг.). DOI: 10.17805/trudy.2017.1.1 